\title{
Off-Grid Power Supply Solution for Portable Cabins using Solar PV System for Qatar
}

\section{Prof. Atif Iqbal, Marif Daula Siddique}

In this project, a new system for power supply for remote area has been proposed. In the proposed system, solar PV based system with battery storage for stand-along application has been discussed. The use of multilevel inverter and high-gain DC/DC converter has been proposed in this system. The proposed multilevel inverter generates nine-level output voltage waveform with quadruple voltage gain. The proposed DC/DC converter is based on the concept of switched-inductor with voltage lift switchedcapacitor and has been verified for a voltage gain of 20 . The experimental results confirmations the satisfactory performance for stand-alone applications of the proposed converters.

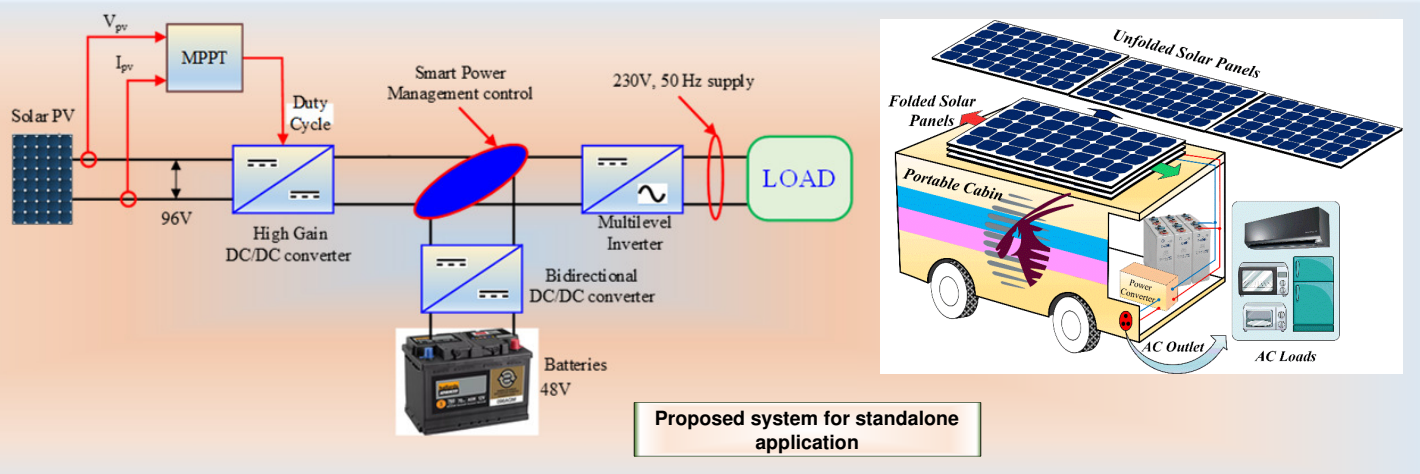

Proposed Quadruple Multilevel Inverter

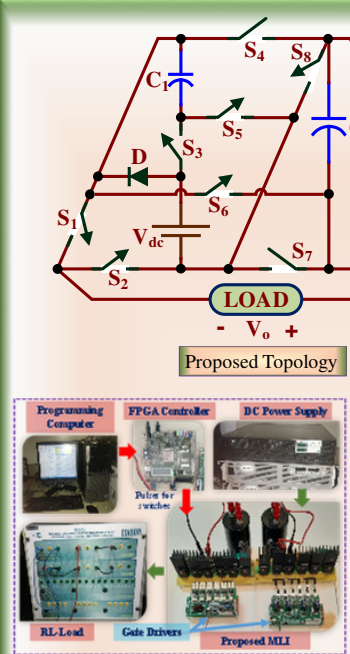

Experimental setup

$>$ Single source configuration

- Requires only two capacitors for a voltage gain of 4

$>10$ switches and one diode is used

> Both capacitors are self-balanced

> Voltage stress of individual devices is lower than the peak output voltage

EXPERIMENTAL PROTOTY Pe DetaIS

\begin{tabular}{|c|c|}
\hline \multicolumn{2}{|c|}{ Key Components } \\
\hline Switches & G60N100 IGBT \\
\hline Capacitor & PG6DI ( $450 \mathrm{~V}$ and $2200 \mu \mathrm{F})$ \\
\hline Controller & FPGA Vertix-5 (XC5VLX50T) \\
\hline Gate Driver & GDA-2A4S1 \\
\hline dc power supply & TDK Lambda GEN300-11 \\
\hline \multicolumn{2}{|c|}{ Key Parameters } \\
\hline $\begin{array}{l}\text { Resistive + Inductive loads } \\
\text { Input dc Link Voltage }\end{array}$ & $\begin{array}{l}\text { Two sets of } 80 \Omega-80 \mathrm{mH} \\
50 \mathrm{~V}\end{array}$ \\
\hline Output Voltage & $200 \mathrm{~V}$ (peak) \\
\hline
\end{tabular}
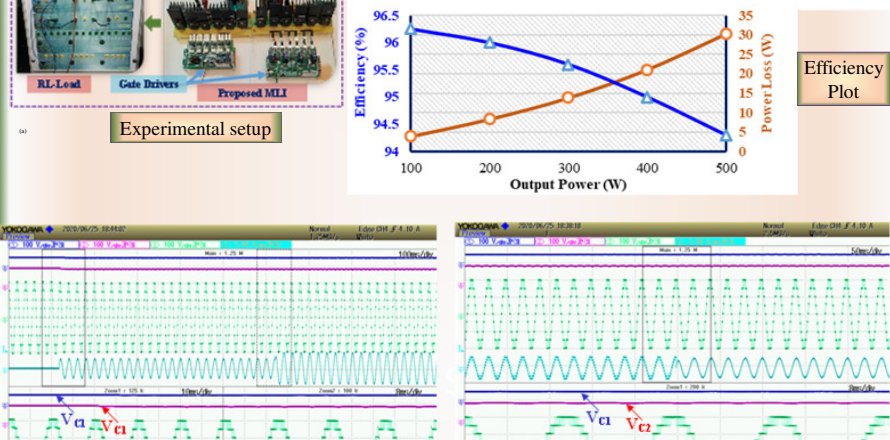

Experimental results of a proposed 9-level inverter with change in RL load $\left[\mathrm{V}_{\mathrm{o}}=100 \mathrm{~V} / \mathrm{div}, \mathrm{V}_{\mathrm{Cl}}=100 \mathrm{~V} / \mathrm{div}\right.$, $\mathrm{V}_{\mathrm{C} 2}=100 \mathrm{~V} / \mathrm{div}$, and $\left.\mathrm{I}_{\mathrm{o}}=5 \mathrm{~A} / \mathrm{div}\right]$

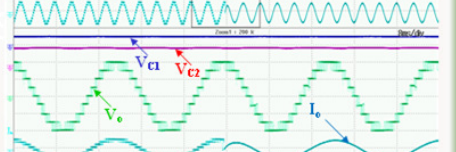

Experimental results of a proposed 9-level inverter with change in load type $\left[\mathrm{V}_{\mathrm{c}}=100 \mathrm{~V} / \mathrm{div}, \mathrm{V}_{\mathrm{C}}=100 \mathrm{~V} / \mathrm{div}\right.$, $\mathrm{V}_{\mathrm{C}}=100 \mathrm{~V} / \mathrm{div}$, and $\left.\mathrm{I}_{\mathrm{n}}=5 \mathrm{~A} / \mathrm{div}\right]$

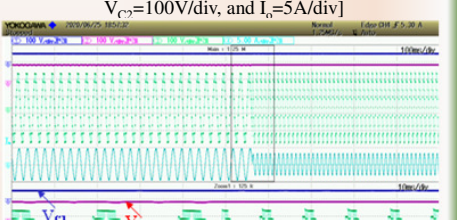

Experimental results of a proposed 9-level inverter with a step change in MI
Experimental results of a proposed 9-level inverter with change in output frequency.

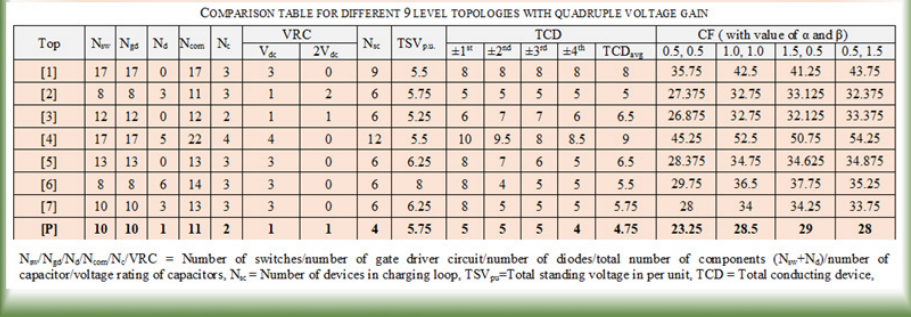

Proposed High-gain DC/DC converter

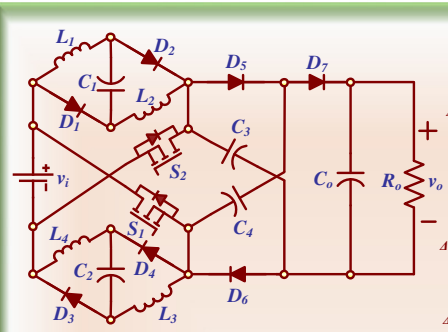

Proposed High-gain DC/DC converter Voltage Gain $\frac{V_{o}}{V_{\text {in }}}=\frac{7+D}{1-D}$

\begin{tabular}{ll} 
& Experimental Parameters \\
\hline Parameter & Value \\
\hline Input voltage & $22 \mathrm{~V}$ \\
Switching frequency & $50 \mathrm{kHz}$ \\
Inductor $\left(\mathrm{L}_{1}\right.$ and $\left.\mathrm{L}_{2}\right)$ & $1 \mathrm{mH}$ \\
Capacitors $\left(\mathrm{C}_{1}\right.$ and $\left.\mathrm{C}_{2}\right)$ & $220 \mathrm{\mu F}$ \\
Capacitor $\mathrm{C}_{\circ}$ & $470 \mathrm{~F}$ \\
Controller & FPGA Vertix-5 (XC5VLX50T) \\
Load Resistance & $400 \Omega-800 \Omega$ \\
\hline
\end{tabular}

\begin{tabular}{l} 
Controller \\
Load Resistance \\
\hline
\end{tabular} $400 \Omega-800 \Omega$
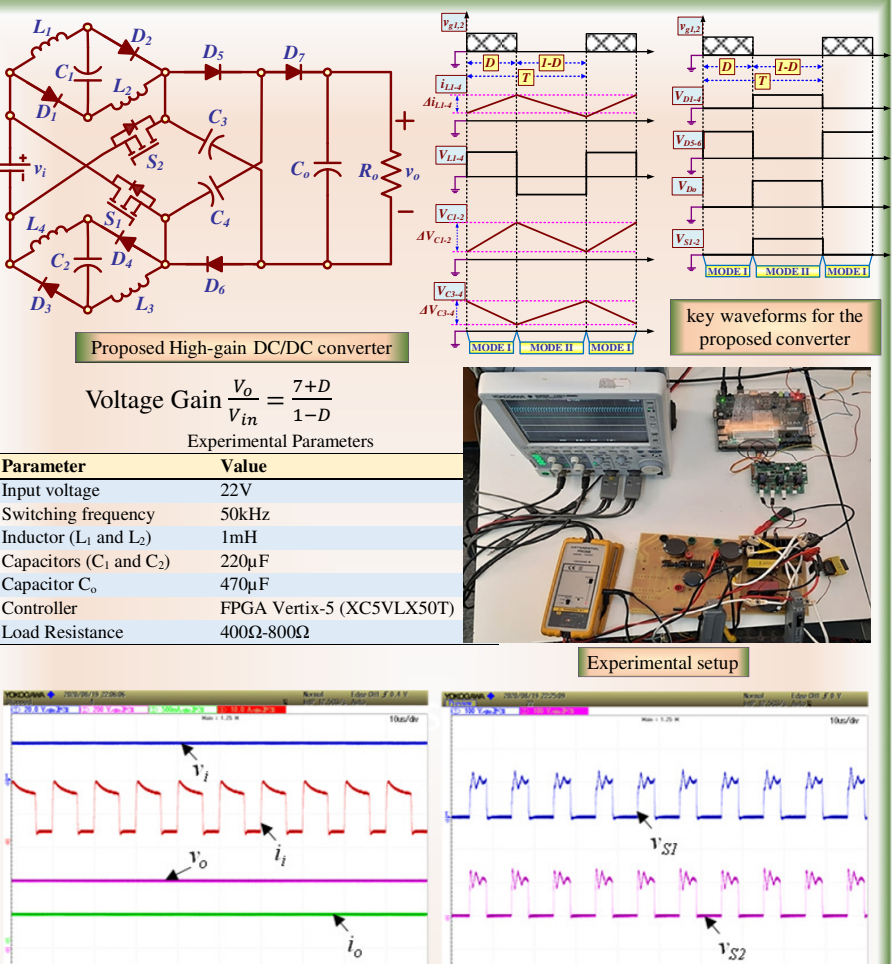

Experimental results of input and output voltage and current and $\mathrm{S}_{2}$

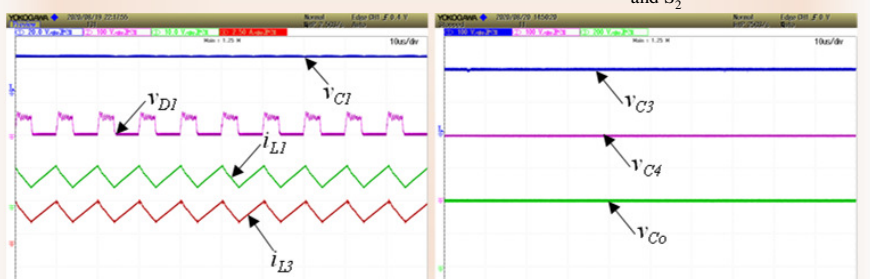

Experimental results of voltage of capacitor $\mathrm{C}_{1}$, diode $\quad$ Experimental results of voltage of capacitor $\mathrm{C}_{3}, \mathrm{C}_{4}$ $\mathrm{D}_{1}$ and inductor current of $i_{L I}$ and $i_{L 3}$ 